\title{
AVALIAÇÃO DOS ASPECTOS E IMPACTOS AMBIENTAIS DE UM LABORATÓRIO DE ANÁLISES FÍSICO-QUÍMICAS PELO MÉTODO FMEA
}

\author{
C.F. AIRES ${ }^{1}$, H. C. D. PIMENTA \\ Instituto Federal de Educação, Ciência e Tecnologia do Rio Grande do Norte, campus Natal Central \\ aires.cynthia@gmail.com ${ }^{1}$
}

Artigo submetido em 25/11/2019 e aceito em 11/12/2019

DOI: $10.15628 /$ holos.2019.9189

\section{RESUMO}

A preocupação com a gestão ambiental é necessária em organizações de diversos porte e setores. Isso também atinge as instituições de ensino, especificamente os laboratórios físico-químicos e suas atividades de ensino, pesquisa e extensão, sendo essas potencialmente poluidoras. Um entendimento dos aspectos e impactos ambientais e estabelecimento de medidas de controle nesses ambientes são cruciais para o planejamento das ações de gestão ambiental. Assim, este trabalho tem como objetivo avaliar os aspectos e impactos ambientais de um laboratório de análises físico-químico do Instituto Federal de Educação, Ciência e Tecnologia do Rio Grande do Norte (IFRN) e propor medidas para controle dos mesmos. Para a realização desta pesquisa, foi
\end{abstract}

desenvolvido um estudo de caso com foco na avaliação dos aspectos e impactos pelo método Failure Mode and Effects Analysis que se baseia na atribuição de valores para severidade, probabilidade e detecção. Os aspectos ambientais relevantes identificados eram associados aos outputs das atividades do laboratório, incluindo resíduos sólidos perigosos, efluente não perigosos e efluente perigoso. À vista disso, foram propostas medidas de controle dos aspectos, levando em consideração as necessidades, a estrutura organizacional e os recursos financeiros. De forma geral, as medidas implementadas tiveram como facilitador o baixo custo, levando a um melhor controle dos aspectos ambientais.

PALAVRAS-CHAVE: Avaliação de aspectos e impactos, gestão ambiental, laboratório de análises físico-químicas.

\section{ENVIRONMENTAL ASPECT AND IMPACT ASSESSMENT ACROSS A PHYSICAL- CHEMICAL LABORATORY THROUGH FMEA}

\begin{abstract}
Environmental management practices are needed across organizations from different sizes and economic sectors. This includes the education institutions, which develop polluting activities, such as physical-chemical laboratories, which are used in teaching, research and extension activities. An understanding of environmental aspects and establishment of environmental control measures across the laboratory are crucial for environmental management. The assessment of the environmental aspect and impact contributes to this performance. Thus, this paper aims to assess the environmental aspect and impact of a physical-chemical laboratory of the federal Institute of Education, Science and Technology, campus Natal, and to propose practices to control them. For that, a case study was carried out
\end{abstract}

focusing on the assessment of environmental aspect and impact through the application of the Failure Mode and Effects Analysis (FMEA) method. FMEA takes into considerations criteria like severity, probability and detection. The significant environmental aspects identified were associated with the outputs of laboratory activities, such as hazardous solid waste, non-hazardous effluent and hazardous effluent. Practices to control the significant environmental aspects were proposed, considering the needs, the organizational structure and the financial resources. Overall, key enabler for the implementation of the practices was the low cost of implementation, leading to a better control of the environmental aspect.

KEYWORDS: Environmental aspect and impact assessment, environmental management, physical-chemical laboratories. 


\section{INTRODUÇÃO}

A preocupação com o aumento do manejo dos recursos naturais tem levado à reflexão sobre seu uso por parte de organizações produtoras e prestadoras de serviços (Assumpção, 2011). Não diferente, a consolidação do compromisso ambiental deve atingir também as instituições de ensino (Vaz, Fagundes, Oliveira, Kovaleski, \& Selig, 2010). Ho e Chen (2018) apontam que a quantidade de universidades vem crescendo constantemente e, com elas, o uso de laboratórios é fundamental para o desenvolvimento de pesquisas. De fato, a teoria alinhada à prática corrobora para a construção do conhecimento, bem como para aquisição dos procedimentos práticos necessários aos alunos (Cho \& Baek, 2019; Queiroga \& Barbalho, 2018).

Todavia, devido às atividades práticas rotineiras, o ambiente laboratorial possui risco elevado e gera aspectos ambientais significativos (por exemplo, geração de resíduos, rejeitos líquidos ou sólidos perigosos, consumo de água e energia). Esses aspectos ambientais têm interação com o meio ambiente e aumentam a potencialidade de consequências, adversas ou benéficas (ABNT, 2015). Assim, faz-se necessária a adoção de mecanismos de controle ambiental (Barbieri, 2007), ainda que tal prática seja um desafio para as instituições, haja vista que são poucas as que desenvolvem a implementação de ferramentas da gestão ambiental (Ho \& Chen, 2018; Tauchen \& Brandli, 2006,). Em adição, a baixa preocupação com a questão ambiental pela alta administração de instituições de ensino foi apontada por Borges et al. (2013) como um entrave para seus laboratórios melhorarem o desempenho ambiental.

A geração de resíduos químicos de laboratórios consiste em um aspecto ambiental que vem sendo solidamente enfatizado na literatura, como, por exemplo, Alberguini, Silva e Rezende (2003), Nascimento e Tenuta Filho (2010) e Lara et al. (2017). Apesar disso, um entendimento mais amplo dos aspectos ambientais gerados por laboratórios analíticos, bem como a utilização de medidas de controle, é necessário. Para tanto, a avaliação dos aspectos ambientais de uma organização consiste em um ponto inicial.

$\mathrm{Na}$ literatura, foram encontrados alguns estudos usando o Failure Mode and Effects Analysis (FMEA) como uma ferramenta de avaliação de aspectos e impactos em laboratórios de instituições de pesquisa. Um deles, em universidades de Taiwan, Ho e Chen (2018) identificaram, por meio do FMEA, os fatores de risco no manejo de resíduos líquidos, sendo, assim, considerado um método eficaz por priorizar os riscos e adotar melhorias, evitando as falhas dos procedimentos. Além disso, Mendonça e Silva (2015) avaliaram os aspectos e impactos ambientais de um laboratório de biologia de uma instituição de ensino no Brasil. Esses estudos constataram que o método FMEA possibilitou não apenas a identificação dos aspectos, mas também a forma de controle para evitar as falhas. Portanto, destaca-se que a utilização do método permite priorizar, por graus de riscos, os aspectos mais relevantes e, por conseguinte, ajudar a instituição na tomada de decisões mais rapidamente e direcionada para evitar as falhas (Peeters; Basten; \& Tinga, 2018). 
Assim, este artigo objetiva avaliar os aspectos e impactos ambientais de um laboratório de análises físico-químicas de uma instituição de ensino, a partir do método FMEA. As seguintes questões-problema norteiam a pesquisa: quais os aspectos e respectivos impactos das atividades realizadas pelo laboratório? Como controlar os aspectos ambientais gerados pelas suas atividades para melhorar seu desempenho ambiental?

\section{METODOLOGIA}

\subsection{Método da pesquisa}

A fim de responder às questões-problema de forma eficiente, esta pesquisa seguiu o estudo de caso (Yin, 2015) como método de coleta de dados. Essa opção metodológica é amplamente utilizada em estudos organizacionais em que os pesquisadores buscam descobrir e interpretar os problemas reais (Senger; Paço-Cunha \& Senger, 2004). De acordo com Yin (2015), as questões-problema, as unidades de análises, a sequência que une os dados e os critérios para coletá-los e analisá-los devem fazer parte de um estudo de caso.

Nesse contexto, o estudo de caso se torna um método amplo quando possibilita incorporar diversas fontes de evidências à coleta e à análise de dados por agregar qualidade à pesquisa na confirmação das descobertas empíricas (Yin, 2015). Desse modo, o estudo tomou como base diferentes métodos de coleta de dados, incluindo: entrevistas, observações em campo, análise documental e grupo focal (Figura 1). Esses elementos foram aplicados em três fases distintas da coleta de dados: a identificação dos aspectos e impactos ambientais do laboratório estudado; a avaliação dos aspectos ambientais pelo método FMEA; e a proposição de medidas de controle para os aspectos encontrados.

Assim, a pesquisa foi desenvolvida no laboratório de maior demanda de análises físicoquímicas do campus central do Instituto Federal Tecnologia do Rio Grande do Norte, na cidade de Natal-RN. O espaço tem a capacidade de processar mensalmente 500 análises, incluindo parâmetros para águas e efluentes oriundos de clientes (aproximadamente 100), de pesquisas científicas dos alunos, dos servidores e dos órgãos conveniados ao instituto.

\subsubsection{Identificação dos aspectos e impactos}

O objetivo de identificar os aspectos ambientais, de acordo com Assumpção (2011), consiste em esclarecer as atividades da organização que possam vir a gerar riscos ou acidentes ambientais, avaliando seus efeitos adversos, falhas e erros no processo. Para o autor, uma maneira de facilitar a identificação dos aspectos ambientais é relacionar as entradas (matérias-primas e insumos) e saídas (produtos acabados e resíduos) associadas às suas atividades, produtos ou serviços.

HOLOS, Ano 35, v.8, e9189, 2019 


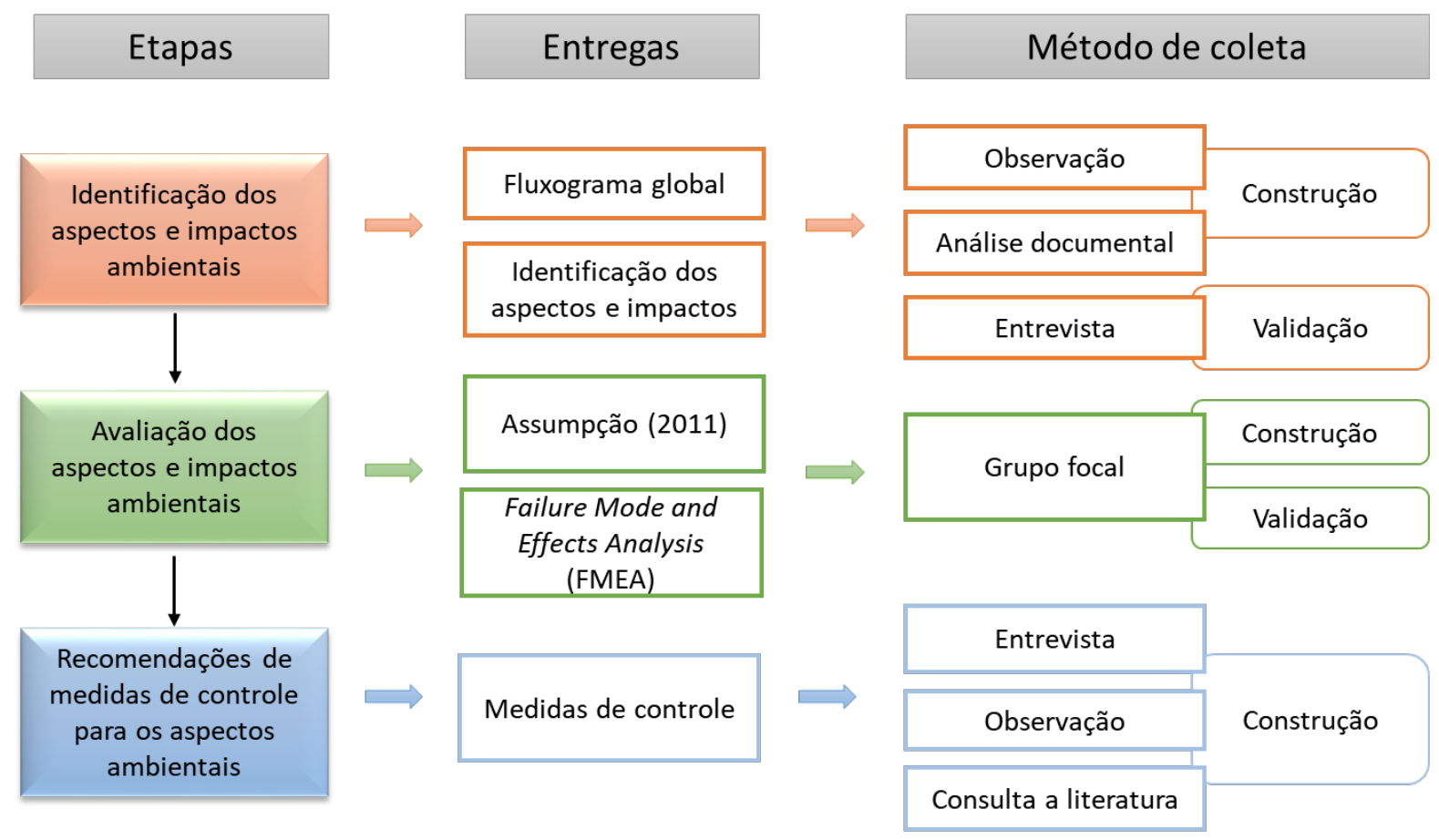

Figura 1: Fluxograma das etapas da pesquisa do laboratório investigado.

Para o levantamento dos aspectos ambientais, foram realizadas observações nas dependências do laboratório em dias e horários alternados durante duas semanas. Além disso, todos os processos de análise de vários parâmetros foram acompanhados, identificando todas as entradas (por exemplo, recursos a serem transformados), equipamentos utilizados, tempo de realização das análises e saídas (por exemplo, subprodutos, poluentes, acondicionamento e descarte dos resíduos e rejeitos gerados).

Também foi realizada uma análise documental dos procedimentos do laboratório acerca das implementações e do cumprimento das normas vigentes. Logo, foi investigado Procedimentos Operacionais Padrão (POP), manual de qualidade, a Resolução da Diretoria Colegiada (RDC) no 11/2012, que dispõe sobre o funcionamento de laboratórios analíticos, o Programa de Prevenção de Riscos Ambientais (PPRA) e formulários diversos para controle interno, bem como a visão da empresa para as questões ambientais. A análise documental facilitou um melhor entendimento das condições de operações e realização das análises, além de aprofundar a identificação de aspectos ambientais potenciais das atividades do laboratório.

Finalmente, as observações proporcionaram uma compreensão do fluxograma global dos processos de analises físico-químicas no laboratório e a identificação dos aspectos e impactos ambientais. Além disso, entrevistas foram usadas para validação dos dados empíricos gerados. Optou-se pela conversacional livre em que a elaboração de perguntas

HOLOS, Ano 35, v.8, e9189, 2019 
surge de acordo com o transcorrer natural da pesquisa, de acordo com as dúvidas e questionamentos do pesquisador (Godoi, Bandeira-Mello \& Silva, 2010). Sendo assim, técnicos de laboratório, estagiários e secretária foram entrevistados. Além de validar os dados empíricos (fluxograma e aspectos e impactos), buscou-se também investigar quais os principais problemas e dificuldades foram enfrentados por eles para desenvolver as práticas de gestão ambiental no local.

\subsubsection{Avaliação dos aspectos e impactos}

$\mathrm{Na}$ avaliação dos aspectos ambientais, foi utilizado o método FMEA por ser um modelo simples e de fácil aplicação. O método atendia a critérios como a necessidade de dar suporte às respostas das perguntas de pesquisa desse tipo, como ao tempo do estudo, sendo possível, assim, constituir bases empíricas nas quais puderam ser definidas medidas de controle para os aspectos identificados.

Além disso, o FMEA se mostrou eficiente em estudos similares para avaliar os aspectos e significância dos aspectos como os de Campani, Coimbra, Fernandes e Birnfeld (2006), Castro Júnior, Bacarji e Bonatti (2011); Matos e Milan (2009) em empresas de pequeno porte; e Carpi Júnior, Borrás e Ferrarini (2015) e Mendonça e Silva (2015) em laboratórios. Carpi Júnior, Borrás e Ferrarini (2015) afirmam que para laboratórios que desejam se regularizar em conformidade com a NBR ISO/IEC 17025:2017, é necessária a melhoria nos seus processos, e para isso, o FMEA se torna um instrumento de análises para evitar as falhas potenciais, aumentando sua confiabilidade.

Com isso, utilizando o método do FMEA, este estudo se baseou na proposta de Assumpção (2011) para análise de fatores ao determinar os aspectos que possam resultar em impactos relevantes ao meio ambiente, tendo uma relação direta com os riscos ambientais. Essa proposta fundamenta-se na atribuição de valores para severidade, probabilidade e detecção quanto ao efeito, ao grau e à condição (Quadro 1), devendo considerar os impactos correspondentes.

A avaliação é pontuada de acordo com seu grau, podendo ser atribuído os valores 1, 3 ou 5 , sendo esse último como mais grave. Com base no valor do grau, foram atribuídas notas para os três fatores (severidade, probabilidade e detecção) e, posteriormente, elas foram compiladas em planilha eletrônica para obtenção da média dos participantes. Dessa forma, a multiplicação dos três fatores acima determina o Índice de Risco Ambiental (IRA) de um aspecto relacionando ao seu impacto, ou seja, a relação de causa e efeito. Assim, se obtém a significância do aspecto, podendo o IRA ser tolerável, moderado ou relevante. Desse modo, foram considerados riscos toleráveis os resultados até 24 , ao passo que valores entre 25 e 99 foram classificados como moderados, e os índices com resultados $>100$ foram considerados relevantes (Quadro 2). 
Quadro 1: Fatores de avaliação do efeito, do grau e da condição.

\begin{tabular}{|c|c|c|c|}
\hline $\begin{array}{l}\text { Fatores } \\
\text { avaliados }\end{array}$ & Efeito & Grau & Condição \\
\hline \multirow[t]{3}{*}{ Severidade } & Leve & 1 & $\begin{array}{l}\text { Impacto localizado com alguma perturbação sobre o meio ambiente } \\
\text { e sem comprometimento legal }\end{array}$ \\
\hline & Grande & 3 & $\begin{array}{l}\text { Impacto localizado com perturbação sobre o meio ambiente e com } \\
\text { comprometimento legal }\end{array}$ \\
\hline & Catastrófico & 5 & $\begin{array}{l}\text { Impacto localizado ou generalizado com perturbação pronunciada } \\
\text { sobre o meio ambiente e com comprometimento legal }\end{array}$ \\
\hline \multirow[t]{3}{*}{ Probabilidade } & Improvável & 1 & Baixíssima possibilidade de ocorrer o dano \\
\hline & Ocasional & 3 & Moderada possibilidade de ocorrer o dano \\
\hline & Certa & 5 & Elevadíssima possibilidade de ocorrer o dano \\
\hline \multirow[t]{3}{*}{ Detecção } & $\begin{array}{l}\text { Certamente } \\
\text { detectável }\end{array}$ & 1 & $\begin{array}{l}\text { O início do problema é facilmente detectável (visual imediato e as } \\
\text { ações corretivas simples e imediatas) }\end{array}$ \\
\hline & Detectável & 3 & $\begin{array}{l}\text { O início do problema é possível de ser detectável (não visual e } \\
\text { identificado por meio do monitoramento rotineiro) }\end{array}$ \\
\hline & $\begin{array}{c}\text { Detectável } \\
\text { somente } \\
\text { com o efeito }\end{array}$ & 5 & $\begin{array}{l}\text { Detectável somente com o dano (não visual e as ações corretivas } \\
\text { são complexas, demoradas e custosas) }\end{array}$ \\
\hline
\end{tabular}

Fonte: Adaptada de Assumpção (2011).

Quadro 2: Escala do índice de risco, tipos de riscos e níveis de ação.

\begin{tabular}{|c|l|l|}
\hline Índice de risco & \multicolumn{1}{|c|}{ Tipo de risco } & \multicolumn{1}{|c|}{ Nível de ação } \\
\hline Até 24 & Riscos toleráveis & $\begin{array}{l}\text { Não necessitam ações imediatas, podendo ser implementadas } \\
\text { quanto a disponibilidade de recursos financeiros e mão de obra }\end{array}$ \\
\hline De 25 a 99 & Riscos moderados & $\begin{array}{l}\text { Requerem previsão e definição a curto prazo e responsabilidade de } \\
\text { implementação de ações }\end{array}$ \\
\hline$>100$ & Riscos relevantes & $\begin{array}{l}\text { Exige a implementação imediata das ações preventivas e de } \\
\text { detecção, com definição de responsabilidades com } \\
\text { acompanhamento e monitoramento contínuo }\end{array}$ \\
\hline
\end{tabular}

Fonte: Adaptada de Assumpção (2011).

Assumpção (2011) recomenda que a avaliação seja realizada pela equipe de trabalho, pois isso reduz o risco de gerar subjetividade dos resultados, devido ao fato da equipe estar próxima da realidade, diferentemente de um investigador externo com informações de fatos isolados, estabelecendo pareceres subjetivos. Dessa forma, a realização da avaliação dos aspectos e impactos ocorreu através da realização de um grupo focal. De acordo com Godoi, Bandeira-Mello e Silva (2010), esse método permite discussões sobre informações acerca de como as pessoas observam um evento, fundamentando às interpretações dos resultados. A avaliação foi conduzida por toda a equipe técnica nas instalações do laboratório, por um período de aproximadamente uma hora. Durante o preenchimento, a discussão possibilitou a interação dos participantes com comentários e opiniões, além de dúvidas que foram esclarecidas pelo moderador (pesquisador). Por último, os resultados foram apresentados durante uma reunião com todos os participantes, para validar os dados empíricos, 
apresentando resposta afirmativa e o consenso de todos.

\subsubsection{Recomendações de medidas de controle para os aspectos ambientais}

O próximo passo após a avaliação foi a elaboração de planos de controle ou monitoramento dos aspectos ambientais identificados. De acordo com Assumpção (2011), as medidas de controle minimizam os efeitos negativos no meio ambiente. Nesse sentido, é possível estabelecer prioridades para o controle dos aspectos mais significativos.

Dessa forma, foram propostas medidas de controle de todos os aspectos, mesmo aqueles considerados toleráveis e que não necessitam de ações emergenciais, apenas com o intuito de manter o controle de todos os aspectos identificados no estudo. As ações foram elaboradas com base em entrevistas com a equipe técnica e a alta administração, bem como observação do processo operacional do laboratório, identificando as necessidades do local, a questão de capacidade organizacional, a disponibilidade de recursos financeiros e a mão de obra da organização. Nessa conjuntura, destaca-se que, para as medidas propostas e implementadas, foi levando em consideração os fatores facilitadores e motivadores.

Para tanto, optou-se por medidas de controle relacionadas às mudanças documentais e organizacionais capazes de causar alterações positivas dentro da instituição, como a conscientização e/ou sensibilização dos colaboradores através da elaboração de POP, do desenvolvimento de treinamento da equipe e de palestras educacionais. Destaca-se que o processo contínuo de aprendizagem leva à transformação organizacional por meio da conscientização, da investigação e da avaliação dos problemas, buscando, desse modo, soluções ou mudanças para a organização (Terence \& Escrivão Filho, 2006).

\section{RESULTADOS E DISCUSSÃO}

\subsection{Descrição das atividades}

Com a etapa de identificação dos aspectos e impactos, foi possível elaborar um fluxograma qualitativo das atividades, contemplando os fluxos de entradas e saídas de matérias-primas e de resíduos, com o intuito de simplificar a identificação dos passivos ambientais do local (Figura 2), sendo base para a identificação dos seus respectivos impactos. 


\section{Laboratório de análises físico-químicas}

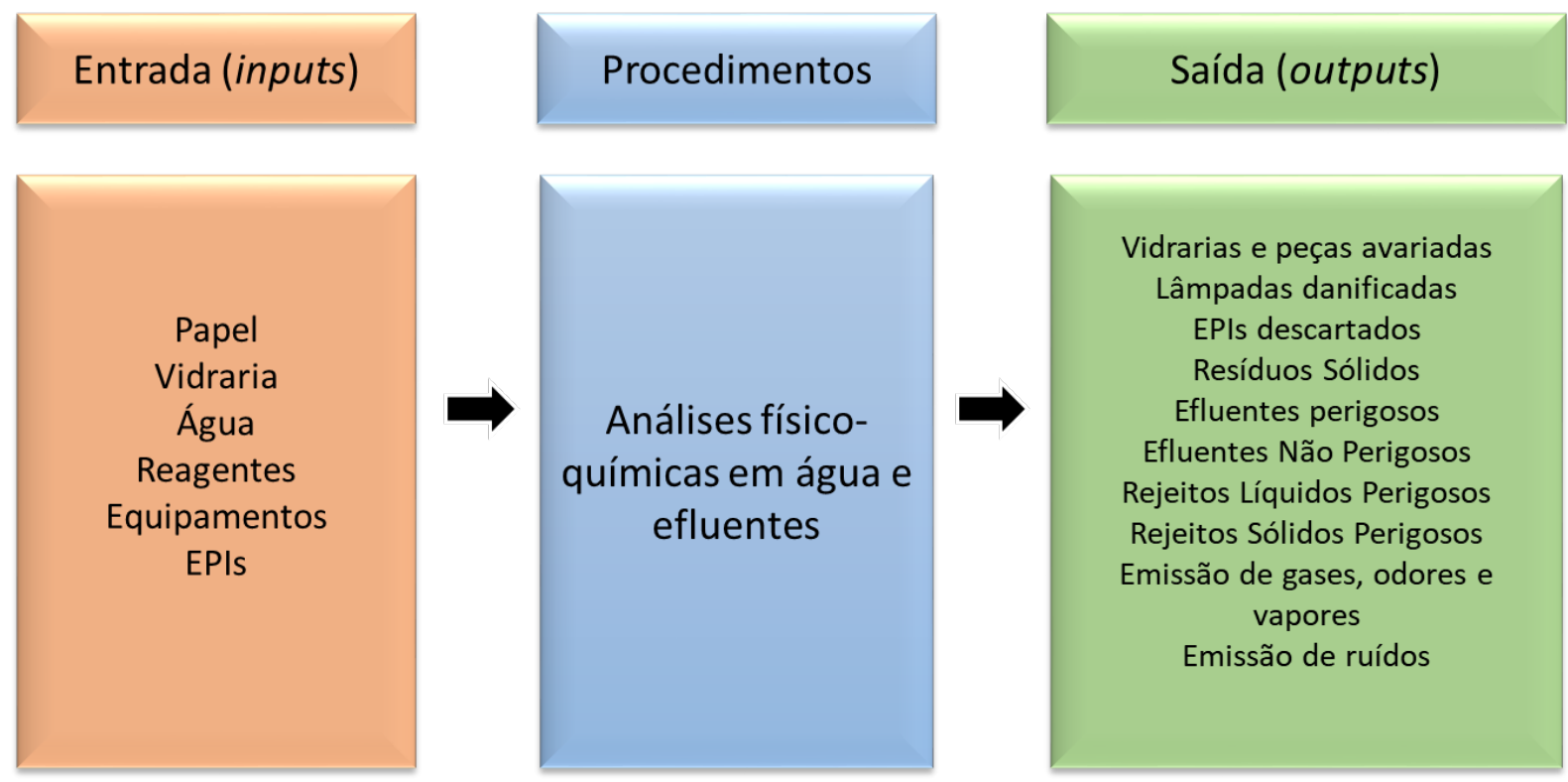

Figura 2: Fluxograma geral das atividades do laboratório.

É preciso destacar que o laboratório analisado opera na realização de análise físicoquímicas completa, de potabilidade simples, de classificação de água para irrigação e aquicultura e de análise de sal e metais pesados, compreendendo 44 parâmetros físicoquímicos e 9 relacionados a metais. Devido a essa extensa lista de análises associada ao tempo de estudo, não foi possível pontuar individualmente cada tipo de parâmetro executado para identificação dos seus respectivos aspectos. Assim, foram consideradas para avaliação as atividades laboratoriais realizadas de forma geral em análises físico-químicas de água e de efluentes.

Pelos resultados, foi evidenciado que as principais ocorrências dos aspectos identificados estão voltadas aos procedimentos das análises, como o consumo de água e de energia devido aos equipamentos e, especialmente, à etapa de saída, como a geração de resíduos sólidos e líquidos, perigosos ou não. É importante frisar ainda o uso diário de diversos tipos de reagentes adicionados para realização das análises os quais são descartados juntamente com o restante das amostras. Os aspectos menos frequentes são a quebra de equipamentos, lâmpadas e emissão de odores e, segundo a alta administração, um ponto importante corresponde ao índice zero de acidentes no laboratório até o presente estudo. Mais detalhes serão apresentados nas descrições dos aspectos no próximo tópico. 
3.2 Análise do nível de aspectos e impactos e ações recomendadas

Os aspectos identificados estão apresentados em tabelas sucintas divididas de acordo com a avaliação do nível de risco, se tolerável ou moderado, e posteriormente com as respectivas medidas de ação recomendadas. Os resultados completos da avaliação dos aspectos e impactos ambientais como também as medidas de controle propostas se encontram no Apêndice $A$.

Seguindo Assumpção (2011), foi avaliado o valor da severidade, que se refere à potencialidade do nível de dano que o impacto ambiental pode produzir; a probabilidade, que analisa a possibilidade de ocorrência de um dano; e a detecção, referente à possibilidade de perceber a ocorrência em sua fase inicial. Os tópicos a seguir apresentam os aspectos ambientais avaliados conforme o IRA, classificados como de riscos toleráveis e moderados. Também serão destacadas algumas medidas de controle implementadas e propostas para o controle dos aspectos ambientais. Finalmente, foram levantados os fatores de sucesso para a implementação das medidas de controle.

\subsubsection{Aspectos ambientais com riscos toleráveis}

Os resultados estão apresentados em uma escala decrescente de pontuação. Dos dez aspectos avaliados, sete foram considerados com riscos toleráveis (Tabela 1). Destaca-se que todos os aspectos foram considerados com grau 3 de severidade, principalmente sob a possibilidade de infringir alguma lei ambiental, além do seu efeito ser considerado grande e o impacto ser localizado com perturbação.

Tabela 1: Resultado detalhado para os aspectos com riscos toleráveis.

\begin{tabular}{lccccc}
\hline \multicolumn{1}{c}{ Aspecto } & \multicolumn{3}{c}{ Fatores } & IRA \\
\cline { 2 - 4 } & Severidade & Probabilidade & Detecção & (SxPxD) \\
\hline $\begin{array}{l}\text { Uso de peças de computadores } \\
\text { equipamentos }\end{array}$ & 3 & 3 & 1 & $\mathbf{9}$ \\
$\begin{array}{l}\text { Acidentes de manipulação } \\
\text { Quebbra de equipamentos e lâmpadas }\end{array}$ & 3 & 3 & 1 & $\mathbf{9}$ \\
Geração de resíduos não perigosos & 3 & 3 & 1 & $\mathbf{9}$ \\
Consumo de energia & 3 & 3 & 1 & $\mathbf{9}$ \\
Consumo de água & 3 & 1 & 3 & $\mathbf{9}$ \\
Odores & 3 & 1 & 3 & $\mathbf{9}$ \\
\hline
\end{tabular}

Quanto à probabilidade, mais de $50 \%$ dos aspectos toleráveis foram interpretados com uma possibilidade moderada do dano vir a ocorrer caso não seja controlado. No que diz respeito à detecção, essa foi o fator que determinou os aspectos no nível tolerável, tendo em

HOLOS, Ano 35, v.8, e9189, 2019 
vista que se compreendeu que a maioria dos problemas que o impacto pode causar são facilmente detectáveis, com exceção do consumo de água e de energia, que requer um monitoramento contínuo, apresentando valor 3. A questão da severidade, por tratar de normas, foi considerada a de maior dificuldade devido demandar conhecimentos legais para nortear as respostas, gerando dúvidas entre os participantes.

Com relação aos odores, esses geralmente ocorrem quando são advindos da realização de análises de efluentes, bem como do seu descarte. Contudo, apesar de incômodo, a dimensão é restrita ao local e a equipe faz o uso de máscaras, sendo, portanto, considerado tolerável. Em pesquisa realizada por Castro Júnior, Bacarji e Bonatti (2011) em laboratórios do Instituto Federal do Mato Grosso, o aspecto odor corresponde da mesma forma com o resultado encontrado no laboratório estudado, por ser um dos aspectos menos significativos. Os autores expõem que a medida de controle utilizada é o exaustor, conforme as ações recomendadas para diminuir potencialmente esse aspecto, evitando, dessa forma, a emissão de odor excessivo.

Relativo ao uso de peças de computadores e equipamentos bem como a quebras de equipamentos e lâmpadas, para todas as análises serem realizadas, é imprescindível a utilização dos mesmos para leitura dos resultados, como também computadores para digitar e organizar os dados. Desse modo, verifica-se que equipamentos como peagâmetro, condutivímetro e estufas necessitam de manutenção contínua para qualidade e confiabilidade dos resultados. Além disso, o uso de peças de computadores e equipamentos, juntamente com a quebra destes, embora sejam considerados resíduos eletrônicos, apresentam baixa frequência e volume insignificante. Esse resultado aproxima-se da pesquisa de Menezes, Silva, Bandeira Filho, Valente e Almeida (2006), em que peças e equipamentos são considerados um risco tolerável e controlado. As ações recomendadas pelos autores consistem em evitar falhas de manutenção para prevenir o desgaste das peças, de modo a não gerar poluição visual ou outro impacto de maior gravidade.

Referente aos riscos de acidentes, de forma a evita-los, os colaboradores são treinados e capacitados a manipularem os equipamentos e reagentes, além de utilizarem os procedimentos operacionais padrão (POP) para realização das atividades. De fato, os riscos de acidentes com produtos químicos diminuem quando a equipe técnica cumpre as exigências de segurança (Al-Zyoud, Qunies, Walters \& Jalsa, 2019). Em complemento aos cuidados, foram identificadas as saídas de emergência bem como equipamentos de proteção coletiva, como chuveiros e lava-olhos em locais estratégicos com rápido acesso em caso de incidentes. À vista disso, foi sugerido treinamento de colaboradores com cursos e a palestras de modo a evitar falhas na manipulação e o manejo incorreto dos equipamentos, vidrarias e reagentes. Esse aspecto, portanto, foi considerado de baixo risco.

Relacionado aos resíduos sólidos não perigosos identificados, são associados a frascos 
e a embalagens de reagentes e papéis. Tais materiais são segregados na fonte e acondicionados em lixeiras próprias para posterior recolhimento pela equipe da limpeza do instituto. Os frascos de reagentes em que a lavagem não é viável devido ao alto consumo de água e detergente para limpeza adequada, são descartados junto com os resíduos perigosos. Com isso, a classificação como tolerável se deu pela ocupação desses materiais não ser em volumes significantes no aterro, já que a quantidade gerada no laboratório é pequena. Uma alternativa sugerida decorre do cadastramento de associações de reciclagem para buscar materiais que possam ser úteis ou o contato com a empresa fabricante de reagentes para estimular a logística reversa desses fracos, com possibilidade de retornar em alguma etapa do ciclo produtivo. É importante destacar, com relação a outros tipos de resíduos como papéis, que existe um espaço reservado de folhas para rascunhos onde eles são reutilizados e cada colaborador também fez a adoção de um copo ou garrafa, diminuindo a quantidade de resíduo gerado.

O aspecto que se refere ao consumo de energia elétrica no local está relacionado majoritariamente ao funcionamento dos equipamentos. Quatro refrigeradores são utilizados initerruptamente para acondicionar amostras e reagentes que demandam temperaturas específicas para não alterar suas características e propriedades. Enfatiza-se ainda o uso contínuo do purificador de água e, quando necessário, o exaustor na capela. Para esse aspecto a severidade foi tida como grande por terem sido levados em consideração os problemas que podem causar ao meio ambiente, além de poder comprometer algum requisito legal, caso não haja $p$ controle. Outro fator que contribuiu para essa pontuação foi a falta de monitoramento do consumo por não se ter instalado, no local, um medidor de energia. Isso dificulta também o estabelecimento de metas de redução de consumo e a própria consciência dos colaboradores quanto ao consumo elevado ou não. Nesse sentido, de acordo com Kaplowitz, Thorp, Coleman e Yeboah (2012), o consumo de energia elétrica de forma não controlada pode causar comprometimento de recursos naturais, sendo, ainda, um dos problemas críticos em laboratórios pelo uso elevado de equipamentos.

Concernente ao consumo de água, são mais relacionados aos procedimentos das análises somados às lavagens de vidrarias e materiais utilizados. Vale destacar que a falta do hidrômetro foi também considerada uma barreira para mensurar o consumo efetivo da água, assim como o medidor para consumo de energia, prejudicando a confiabilidade da avaliação desses aspectos exatamente por não poder comparar o valor estimado de uso e, consequentemente, afirmar sua significância. A mensuração de aspectos ambientais (por exemplo, o consumo de água e de energia) é a base do estabelecimento de metas e de programas ambientais, haja vista que mudanças em níveis estratégicos e operacionais têm a capacidade de impulsionar inovações como a implementação de práticas ambientais, que são um dos mecanismos da gestão ambiental (Pimenta \& Gouvinhas, 2012). De modo a melhorar seu desempenho ambiental, o laboratório estudado vem implementando práticas com o 
intuito de reduzir o consumo de água. Por exemplo, o equipamento destilador foi substituído tendo em vista que utiliza em média $15 \mathrm{~L}$ de água para produzir $1 \mathrm{~L}$ de água destilada (Tavares \& Bendassolli, 2005). Por outro lado, os purificadores mantêm uma proporcionalidade de consumo e produção de água purificada não desperdiçando a água utilizada. É importante notar que as medidas implementadas para o melhor controle do uso da água têm reduzido a severidade e a probabilidade do consumo de água. Tal realidade pode justificar o aspecto ter sido classificado como risco tolerável. Esse resultado também foi identificado por estudos em laboratórios de instituições de ensino como os de Mendonça e Silva (2015) e Cerezini, Amaral e Polli (2016).

\subsubsection{Aspectos ambientais com riscos moderados}

Os aspectos com riscos moderados são aqueles com magnitude considerável quanto ao risco ofensivo ao meio ambiente (Assumpção, 2011). A Tabela 2 apresenta os aspectos ambientais avaliados por ordem de importância. O aspecto mais preponderante em significância foi a geração de efluente perigoso. Os entrevistados consideraram o impacto generalizado, podendo comprometer leis ambientais e detectar o impacto apenas quando o dano ocorrer. Os detalhes da avaliação serão apresentados nos próximos tópicos.

Tabela 2: Resultado detalhado para os aspectos com riscos moderados.

\begin{tabular}{lccccc}
\hline \multicolumn{1}{c}{ Aspecto } & \multicolumn{3}{c}{ Fatores } & IRA \\
\cline { 2 - 4 } & Severidade & Probabilidade & Detecção & (SxPXD) \\
\hline Geração de efluente perigoso & 5 & 3 & 5 & $\mathbf{7 5}$ \\
Geração de efluente não perigoso & 3 & 3 & 5 & $\mathbf{4 5}$ \\
Geração de resíduos sólidos perigosos & 5 & 5 & 1 & $\mathbf{2 5}$ \\
\hline
\end{tabular}

Os resíduos sólidos perigosos do laboratório são provenientes, por exemplo, das análises derivadas de óleos e graxas, como também de clorofila. A probabilidade de ocorrência foi avaliada com elevada possibilidade por ser um aspecto frequente das atividades no local. Contudo, foi interpretada como de fácil detecção, já que possivelmente o início do problema é perceptível ao contaminar o solo ou águas, sendo assim atribuído o valor 1. Em contraste, destaca-se que atualmente o laboratório realiza o acondicionamento desses resíduos perigosos em bombonas plásticas e o armazenamento temporário em uma área coberta e isolada para a posterior destinação final por empresa especializada. Mesmo assim, esse aspecto ambiental foi considerando um risco moderado sob a justificativa de ser controlado. Esse resultado corrobora com os encontrados nos estudos de Mendonça e Silva (2015) que identificaram também esse aspecto como significativo no laboratório de biologia.

De outro modo, os efluentes não perigosos são provenientes dos remanescentes das amostras de água, de rio, de poços e de praia, em que o descarte é feito diretamente na pia 
por não oferecerem riscos relevantes ao meio ambiente. A resolução CONAMA no 430/2011, que dispõe sobre as condições e os padrões de lançamento de efluentes, no Art. 16, aborda que, se obedecerem às condições e padrões previstos, os efluentes de qualquer fonte poluidora podem ser lançados diretamente no corpo receptor (CONAMA, 2011). Baseado nisso, as amostras de efluentes tratados são assim descartadas. A justificativa dos participantes para esse aspecto ambiental ser considerado moderado foi o fato de haver geração de alto volume de efluentes pelo laboratório, necessitando, portanto, de um controle contínuo. Para Alberguini, Silva e Rezende (2003), existe, de fato, um certo risco no gerenciamento dos efluentes de laboratórios devido à dependência da conscientização e do envolvimento dos colaboradores.

Por fim, a geração de efluente perigoso decorre das análises como metais pesados, cloro, nitrato, análises de efluentes hospitalar, entre outros. Esse aspecto foi considerado como mais significativo por apresentar capacidade altamente poluidora ao meio ambiente. 0 resultado concorda com estudos de Penatti e Guimarães (2011) e Mendonça e Silva (2015), em laboratórios, haja vista que a geração de efluentes líquidos representa um dos aspectos mais significativos devido às diferentes características dos compostos e reagentes utilizados nas análises realizadas, apresentando risco potencial de impacto adverso tanto à saúde humana quanto ao meio ambiente (Ho \& Chen, 2018). Atualmente, a medida de controle usada consiste no acondicionamento em bombonas de 200 litros e armazenamento na sala de rejeitos de acordo com os seguintes grupos: metais, orgânicos, inorgânicos, voláteis, efluentes e rejeito sólido. Em seguida, uma empresa devidamente licenciada faz o transporte e tratamento através da incineração.

O armazenamento dos resíduos gerados pelos laboratórios configura-se como um passivo ambiental devido ao grande volume acondicionado, principalmente se associado às condições precárias da estrutura física do local (Alberguini, Silva \& Rezende, 2003). Essa questão fundamenta o resultado encontrado, priorizando importância no controle efetivo desse aspecto. Uma medida proposta foi a elaboração de um sistema para garantir $100 \%$ de gerenciamento de todo processo. Como reforça Foster (2005), a gestão de materiais perigosos em laboratórios é um fator crítico, e a sua gestão eficiente fundamenta-se no gerenciamento de todo seu processo, sendo necessário o uso de procedimentos para garantir o manuseio, o armazenamento e o transporte dos produtos químicos até a disposição.

\subsection{Contexto para implementação das medidas propostas}

Entre as medidas propostas e implementadas, destacam-se o aumento da frequência da coleta desses rejeitos pela empresa especializada, o uso do POP para controle dos rejeitos perigosos e de planilhas de monitoramento. Através da planilha, passou-se a ter um controle da entrada e saída de resíduos de forma a garantir $100 \%$ da rastreabilidade do rejeito.

HOLOS, Ano 35, v.8, e9189, 2019 
Um fator facilitador para a implementação dessas medidas foi o investimento de baixo custo necessário. O comprometimento, o nível de formação e a capacitação da equipe foram também facilitadores identificados. Ribeiro, Pedreira Filho e Reiderer (2007) apontaram que a falta de conscientização dos colaboradores e a ausência de procedimentos devidamente escritos como os POPs, por exemplo, são barreiras na implementação de medidas para controle dos agentes químicos no ambiente de trabalho. Finalmente, quanto aos fatores motivadores para a implementação dessas medidas, a busca pela conformidade com os requisitos da norma NBR ISO/IEC 17025:2017, que propõe o desenvolvimento de um Sistema de Gestão de Qualidade (SGQ) em laboratórios, foi o principal fator motivador identificado.

\section{CONCLUSÕES}

A realização deste estudo possibilitou um maior conhecimento dos processos e serviços laboratoriais investigados por meio da utilização do FMEA. Isso inclui também uma maior consciência sobre os aspectos e impactos ambientais gerados pelas atividades e a necessidade do uso de medidas controle deles. Diante dos resultados encontrados, constatouse que os maiores riscos ambientais existentes no âmbito do laboratório correspondem à geração de efluente perigoso, geração de efluente não perigoso e geração de resíduos sólidos perigosos, respectivamente em ordem de significância. À vista disso, foi sugerido a continuação da implementação de medidas de controle, em especial, o direcionamento de mudanças para melhorias desses três aspectos mais relevantes, a fim de reduzir o índice de risco ambiental de moderado para tolerável.

Vale destacar que o laboratório já faz a destinação do rejeito sólido e líquido perigoso por empresa especializada, entretanto, não existia um plano de gerenciamento de controle de entrada e saída de material, não garantindo, portanto, $100 \%$ de rastreabilidade. Contudo, melhorias ainda são necessárias no processo das atividades para minimizar possíveis impactos negativos ao meio ambiente. As principais barreiras encontradas na implementação das medidas de controle referem-se à ausência de um gestor ambiental atrelada à limitação financeira. Por outro lado, a melhoria no processo das atividades gerais do laboratório foi umas das principais contribuições do estudo. Isso foi possível devido à proposição de mudanças documentais e organizacionais, assim como a implementação de práticas ambientais de baixo custo, levando a um maior controle dos aspectos com atividades menos poluidoras.

Uma limitação encontrada no uso do FMEA consistiu na subjetividade de cada participante em relacionar a pontuação a ser dada a cada fator, tornando-se imprescindível o consenso dos envolvidos para validação dos resultados. Esses elementos podem ser levados em consideração em pesquisas futuras.

HOLOS, Ano 35, v.8, e9189, 2019 


\section{REFERÊNCIAS}

ABNT NBR ISO/IEC 17025, de 10 de dezembro de 2017. Requisitos gerais para a competência, imparcialidade e operação consistente dos laboratórios. Rio de Janeiro: Associação Brasileira de Normas Técnicas. Recuperado de http:// http://www.abnt.org.br/imprensa/releases/5685-publicada-a-nova-versao-da-iso-iec17025.

ABNT NBR ISO 14001, de 6 de outubro de 2015. Sistema de Gestão Ambiental: Requisitos com orientações para uso. Rio de Janeiro: Associação Brasileira de Normas Técnicas. Recuperado de http://abnt.org.br/paginampe/noticias/218-abnt-nbr-iso-14001-2015sistemas-de-gest\%C3\%A3o-ambiental-\%E2\%80\%94-requisitos-comorienta\%C3\%A7\%C3\%B5es-para-uso.

ALBERGUINI, L. B. A., SILVA, L. C., REZENDE, M. O. O. (2003). Laboratório de resíduos químicos do campus USP-São Carlos - resultados da experiência pioneira em gestão e gerenciamento de resíduos químicos em um campus universitário. Quim. Nova, v. 26, n. 2, p. 291-295.

AL-ZYOUD, W., QUNIES, A. M, WALTERS, A. U \& JALSA, N. K. (2019). Perceptions of Chemical Safety in Laboratories. Safety, v. 5, n. 21.

ASSUMPÇÃO, L. F. J. (2011). Sistema de Gestão Ambiental: manual prático para implementação de SGA e Certificação ISO 14.001 (3a ed). Curitiba: Juruá.

BARBIERI, J. C. (2007). Gestão ambiental empresarial: conceitos, modelos e instrumentos. São Paulo: Saraiva.

BORGES, A. F. et al. (2013). Análise da gestão ambiental nos Institutos Federais de Educação, Ciência e Tecnologia. Cerne, v. 19, n. 2, p. 177-184.

CAMPANI, D. B., COIMBRA, N. S., FERNANDES, T. G. \& BIRNFELD, E. F. (2006). Implementação do sistema de gestão ambiental no prédio da engenharia mecânica - UFRGS. Anais do Congresso Interamericano de Ingeniería Sanitaria Y Ambiental, Punta del Este, Maldonado, Uruguai, 30. Recuperado de https://docplayer.com.br/16567435Implementacao-do-sistema-de-gestao-ambiental-no-predio-da-engenharia-mecanicaufrgs.html.

CARPI JÚNIOR, E. J., BORRÁS, M. A. A., FERRARINI, C. F. (2015). Implantação do FMEA em Laboratório para a Melhoria dos Processos de Pesquisa: um estudo de caso. Anais do Simposio de Ingeniería de la Producción Sudamericano, Sorocaba, SP, Brasil, 15. Recuperado de https://www.researchgate.net/publication/281551736_Implantacao_do_FMEA_em_La boratorio_para_a_Melhoria_dos_Processos_de_Pesquisa_um_estudo_de_caso/link/55 
ed7a1108ae3e1218480b88/download.

CASTRO JÚNIOR, E. J., BACARJI, A. G. \& BONATTI, J. (2011). Levantamento de aspectos e impactos ambientais do instituto federal de educação, ciência e tecnologia de Mato Grosso, campus Cuiabá-Bela Vista. Anais do Congresso Brasileiro de Gestão Ambiental, Londrina, PR, Brasil, $2 . \quad$ Recuperado de https://www.ibeas.org.br/congresso/Trabalhos2011/I-014.pdf.

CEREZINI, M. T., AMARAL, K. M. \& POLLI, H. Q. (2016). Avaliação dos aspectos e impactos ambientais em uma instituição de ensino com o uso da ferramenta FMEA. Saúde, Meio Ambiente e Sustentabilidade, São Paulo, v. 11, n. 1.

CHO, J. \& BAEK, W. (2019). Identifying Factors Affecting the Quality of Teaching in Basic Science Education: Physics, Biological Sciences, Mathematics, and Chemistry. Sustainability, 11, 3958, p. 2-18.

CONSELHO NACIONAL DO MEIO AMBIENTE - CONAMA (2011). Resolução no 430, de 13 de maio de 2011. Dispõe sobre as condições e padrões de lançamento de efluentes, complementa e altera a Resolução no 357, de 17 de março de 2005, do Conselho Nacional do Meio Ambiente CONAMA. Diário Oficial da República Federativa do Brasil, Ministério do Meio Ambiente, Brasília.

FOSTER. B. L. (2005). The Chemical Inventory Management System in academia. Journal of Chemical Health \& Safety, v. 12, n. 5, p. 21-25.

GODOI, C. K., BANDEIRA-DE-MELLO, R. \& SILVA, A. N. (2010). Pesquisa qualitativa em estudos organizacionais: paradigmas, estratégias e métodos (4a. ed). São Paulo: Saraiva.

HO, C. C. \& CHEN, M. S. (2018). Risk assessment and quality improvement of liquid waste management in Taiwan University chemical laboratories. Waste Management, 71, p. 578588.

KAPLOWITZ, M. D.; THORP, L.; COLEMAN, K.; \& YEBOAH, F. K. (2012). Energy conservation attitudes, knowledge, and behaviors in science laboratories. Energy Policy, 50, p. 581-591.

LARA, E. R., DE LA ROSA, J. R., CASTILLO, A. I. R., CERINO-CORDOVA, F. J., CHUKEN, U. J. L., DELGADILLO, S. S. F. \& RIVAS-GARCÍA, P. (2017). A comprehensive hazardous waste management program in a Chemistry School at a Mexican university. Journal of Cleaner Production, 142, p. 1488-1491.

MATOS, R. B. \& MILAN, M. (2009). Aplicação sistêmica do modo de análise de falhas e efeitos (FMEA) para o desenvolvimento de indicadores de desempenho de empresas de pequeno porte. R. Árvore, v.33, n.5, p. 977-985.

MENDONÇA, J. M. S. \& SILVA, R. G. (2015). Aspectos e impactos ambientais de um laboratório 
de biologia. Holos, v. 8, n. 31, p. 368-383.

MENEZES, J. R. B., SILVA, J. J. R., BANDEIRA FILHO, O. M., VALENTE, M. C. B. S. \& ALMEIDA, M. L. (2006). Contribuição para a identificação de aspectos ambientais e impactos significativos na gestão da construção de edificações urbanas. In: SIMPÓSIO DE ENGENHARIA DE PRODUÇÃO, 13, 2006. Bauru. Anais eletrônicos... Bauru, UNESP.

NASCIMENTO, E. S. \& TENUTA FILHO, A. (2010). Chemical waste risk reduction and environmental impact generated by laboratory activities in research and teaching institutions. Brazilian Journal of Pharmaceutical Sciences, v. 46, n. 2, p. 187-198.

PEETERS, J.F.W., BASTEN, R.J.I. \& TINGA, T. (2018). Improving failure analysis efficiency by combining FTA and FMEA in a recursive manner. Reliability Engineering and System Safety, v. 172, p. 36-44.

PENATTI, F. E. \& GUIMARÃES, S. T. L. (2011). Avaliação dos riscos e problemas ambientais causados pela disposição incorreta de resíduos de laboratórios. Geografia Ensino \& Pesquisa, v. 15, n. 1.

PIMENTA, H. C. D. \& GOUVINHAS, R. P. (2012). A produção mais limpa como ferramenta da sustentabilidade empresarial: um estudo no estado do Rio Grande do Norte. Produção, v. 22, n. 3, p. 462-476.

RESOLUÇÃO RDC n. 11, de 16 de fevereiro de 2012. Dispõe sobre o funcionamento de laboratórios analíticos que realizam análises em produtos sujeitos à Vigilância Sanitária e dá outras providências. Recuperado de http://portal.anvisa.gov.br/documents/10181/2867923/(1)RDC_11_2014_COMP.pdf/5e 552d92-f573-4c54-8cab-b06efa87036e.

RIBEIRO, M. G., PEDREIRA FILHO, W. R. \& RIEDERER, E. E. (2011). Avaliação qualitativa de riscos químicos: orientações básicas para o controle da exposição a produtos químicos em fundições. p. 93. São Paulo, SP.

SENGER, I., PAÇO-CUNHA, E. \& SENGER, C. M. (2004). O estudo de caso como estratégia metodológica de pesquisas científicas em administração: um roteiro para o estudo metodológico. Revista de Administração, v. 3, n. 4.

TAUCHEN, J. \& BRANDLI, L. (2006). A Gestão Ambiental em Instituições de Ensino Superior: Modelo para Implantação em Campus Universitário. Gestão e Produção, v.13, n.3, p.503515.

TAVARES, G. A. \& BENDASSOLLI, J. A. (2005). Implantação de um programa de gerenciamento de resíduos químicos e águas servidas nos laboratórios de ensino e pesquisa no CENA/USP. Quim. Nova, v. 28, n. 4, p. 732-738. 
TERENCE, A. C. F. \& ESCRIVÃO FILHO, E. (2006). Abordagem quantitativa, qualitativa e a utilização da pesquisa-ação nos estudos organizacionais. In: ENCONTRO NACIONAL DE ENGENHARIA DE PRODUÇÃO, 26, 2006, Fortaleza. Anais eletrônicos... Fortaleza: Associação Brasileira de Engenharia de Produção.

VAZ, C. R., FAGUNDES, A. B., OLIVEIRA, I. L., KOVALESKI, J. L. \& SELIG, P. M. (2010). Sistema de Gestão Ambiental em Instituições de Ensino Superior: uma revisão. Gestão da Produção, Operações e Sistemas. v. 5, n. 3, p. 45-58.

YIN, R. K. (2015). Estudo de caso: planejamento e métodos (5a ed.). Porto Alegre: Bookman. 
APÊNDICE - RESULTADO DO FMEA PARA OS PROCESSOS DAS ATIVIDADES DO LABORATÓRIO

\begin{tabular}{|c|c|c|c|c|c|c|c|c|c|}
\hline \multirow{2}{*}{ Aspecto } & Modo de Falha & \multirow{2}{*}{ Impacto } & \multirow{2}{*}{ 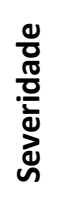 } & \multirow{2}{*}{$\begin{array}{l}\frac{0}{0} \\
\frac{\pi}{0} \\
\frac{0}{0} \\
\frac{0}{0} \\
\frac{0}{0} \\
\frac{2}{2}\end{array}$} & \multirow{2}{*}{ 胥 } & \multirow{2}{*}{ Modo atual de controle } & \multirow{2}{*}{ 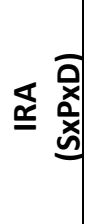 } & \multirow{2}{*}{ 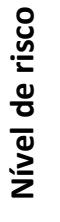 } & \multirow{2}{*}{ Medidas de controle propostas } \\
\hline & Causa do modo de falha & & & & & & & & \\
\hline \multirow{2}{*}{$\begin{array}{l}\text { Uso de peças de } \\
\text { computadores } \\
\text { e equipamentos }\end{array}$} & Falha de manutenção & \multirow{2}{*}{ Escassez do recurso natural } & \multirow{2}{*}{3} & \multirow{2}{*}{3} & \multirow{2}{*}{1} & \multirow{2}{*}{$\begin{array}{l}\text { Segregação e descarte } \\
\text { para coleta }\end{array}$} & \multirow{2}{*}{9} & \multirow{2}{*}{$\mathbf{T}$} & \multirow{2}{*}{$\begin{array}{l}\text { Aumentar a frequência da manutenção das } \\
\text { peças }\end{array}$} \\
\hline & Desgaste das peças & & & & & & & & \\
\hline \multirow{2}{*}{ Odores } & $\begin{array}{l}\text { Emissão de odor } \\
\text { excessivo }\end{array}$ & \multirow{2}{*}{$\begin{array}{l}\text { Alteração da qualidade do } \\
\text { ar/ incômodo aos } \\
\text { colaboradores e clientes }\end{array}$} & \multirow{2}{*}{3} & \multirow{2}{*}{1} & \multirow{2}{*}{1} & \multirow{2}{*}{ Não há controle } & \multirow{2}{*}{3} & \multirow{2}{*}{$\mathbf{T}$} & \multirow{2}{*}{$\begin{array}{l}\text { Instalação de um exaustor na sala de preparo } \\
\text { e filtro na capela }\end{array}$} \\
\hline & Ausência de exaustor & & & & & & & & \\
\hline \multirow{2}{*}{$\begin{array}{l}\text { Acidentes de } \\
\text { manipulação }\end{array}$} & $\begin{array}{l}\text { Falha na manipulação } \\
\text { pelos colaboradores }\end{array}$ & \multirow{2}{*}{$\begin{array}{c}\text { Contaminação do ambiente } \\
\text { e } \\
\text { do manipulador }\end{array}$} & \multirow[t]{2}{*}{3} & \multirow[t]{2}{*}{3} & \multirow[t]{2}{*}{1} & \multirow{2}{*}{$\begin{array}{l}\text { Seguir recomendações } \\
\text { dos POPs }\end{array}$} & \multirow[t]{2}{*}{9} & \multirow[t]{2}{*}{$\mathbf{T}$} & \multirow{2}{*}{$\begin{array}{l}\text { Treinamento de colaboradores com cursos e } \\
\text { a palestras }\end{array}$} \\
\hline & Manejo incorreto & & & & & & & & \\
\hline \multirow{2}{*}{$\begin{array}{l}\text { Quebra de } \\
\text { equipamentos } \\
\text { e lâmpadas }\end{array}$} & $\begin{array}{l}\text { Falha de manutenção e } \\
\text { manipulação pelos } \\
\text { colaboradores }\end{array}$ & Escassez do recurso natural & 3 & 3 & 1 & Segregação e descarte & 9 & $\mathbf{T}$ & $\begin{array}{l}\text { Aumentar a frequência da manutenção das } \\
\text { peças }\end{array}$ \\
\hline & Desgaste das peças & & & & & & & & $\begin{array}{c}\text { Treinamento de colaboradores com cursos e } \\
\text { a palestras }\end{array}$ \\
\hline & $\begin{array}{l}\text { Falhas nas medidas de } \\
\text { controle do uso }\end{array}$ & & & & & & & & $\begin{array}{c}\text { Educação ambiental contínua por meio de } \\
\text { palestras educacionais e treinamentos da } \\
\text { equipe }\end{array}$ \\
\hline $\begin{array}{l}\text { Consumo de } \\
\text { energia }\end{array}$ & $\begin{array}{l}\text { Ausência de ações de } \\
\text { conscientizacão e }\end{array}$ & Escassez do recurso natural & 3 & 1 & 3 & Não há controle & 9 & $\mathbf{T}$ & $\begin{array}{l}\text { Elaboração de guia de boas práticas } \\
\text { sustentáveis para evitar o desperdício e } \\
\text { contribuir para o uso consciente }\end{array}$ \\
\hline & educação ambiental & & & & & & & & $\begin{array}{c}\text { Instalação de um medidor para mensuração } \\
\text { da quantidade de energia consumida por } \\
\text { mês }\end{array}$ \\
\hline HOLOS, A & 35, v.8, e9189, 2019 & & & & & 20 & & & \\
\hline
\end{tabular}




\begin{tabular}{|c|c|c|c|c|c|c|c|c|c|}
\hline \multirow{3}{*}{$\begin{array}{l}\text { Consumo de } \\
\text { água }\end{array}$} & $\begin{array}{l}\text { Falhas nas medidas de } \\
\text { controle do uso (vazão } \\
\text { inadequada) }\end{array}$ & \multirow{3}{*}{ Escassez do recurso natural } & \multirow{3}{*}{3} & \multirow{3}{*}{1} & \multirow{3}{*}{3} & $\begin{array}{l}\text { Troca de equipamento } \\
\text { com consumo reduzido } \\
\text { Utilização do mínimo de } \\
\text { amostra possível para } \\
\text { realizar a análise }\end{array}$ & \multirow{3}{*}{9} & \multirow{3}{*}{$\mathbf{T}$} & $\begin{array}{c}\text { Instalação de um hidrômetro para } \\
\text { mensuração da quantidade de água utilizada } \\
\text { por mês }\end{array}$ \\
\hline & \multirow{2}{*}{$\begin{array}{l}\text { Ausência de mais ações } \\
\text { de conscientização e } \\
\text { educação ambiental }\end{array}$} & & & & & \multirow[t]{2}{*}{$\begin{array}{l}\text { Utilização do mínimo de } \\
\text { amostra possível para } \\
\text { realizar a análise }\end{array}$} & & & $\begin{array}{c}\text { Programa de redução de consumo em 5\%: } \\
\text { modificação no processo através do uso na } \\
\text { marcação das torneiras até uma vazão que } \\
\text { seja suficiente a quantidade de água para } \\
\text { análise. }\end{array}$ \\
\hline & & & & & & & & & $\begin{array}{c}\text { Elaboração de guia de boas práticas } \\
\text { sustentáveis para evitar o desperdício e } \\
\text { contribuir para o uso consciente }\end{array}$ \\
\hline \multirow{2}{*}{$\begin{array}{l}\text { Geração de } \\
\text { resíduos não } \\
\text { perigosos } \\
\text { (Recicláveis) }\end{array}$} & $\begin{array}{l}\text { Utilização de produtos } \\
\text { durante o processo }\end{array}$ & \multirow{2}{*}{$\begin{array}{l}\text { Ocupação do aterro } \\
\text { sanitário e poluição visual }\end{array}$} & \multirow{2}{*}{3} & \multirow{2}{*}{3} & \multirow{2}{*}{1} & \multirow{2}{*}{$\begin{array}{l}\text { Segregação e descarte } \\
\text { para coleta }\end{array}$} & \multirow{2}{*}{9} & \multirow{2}{*}{$\mathbf{T}$} & $\begin{array}{c}\text { Logística reversa dos recipientes para } \\
\text { reaproveitamento no ciclo produtivo ou } \\
\text { outra forma de reciclagem }\end{array}$ \\
\hline & $\begin{array}{l}\text { Consumo elevado de } \\
\text { reagentes }\end{array}$ & & & & & & & & $\begin{array}{l}\text { Cadastramento das Associações e } \\
\text { Cooperativas de reciclagem }\end{array}$ \\
\hline \multirow{3}{*}{$\begin{array}{l}\text { Geração de } \\
\text { efluentes } \\
\text { não perigosos }\end{array}$} & Descarte inadequado & \multirow{3}{*}{$\begin{array}{l}\text { Alteração da qualidade da } \\
\text { água }\end{array}$} & \multirow{3}{*}{3} & \multirow{3}{*}{3} & \multirow{3}{*}{5} & \multirow{3}{*}{ Não há controle } & \multirow{3}{*}{45} & \multirow{3}{*}{ M } & $\begin{array}{l}\text { Redução da quantidade de reagentes e } \\
\text { desperdícios na fonte do processo produtivo }\end{array}$ \\
\hline & \multirow[t]{2}{*}{$\begin{array}{l}\text { Tratamento inviável } \\
\text { financeiramente }\end{array}$} & & & & & & & & $\begin{array}{l}\text { Elaboração de Procedimento Operacional } \\
\text { Padrão (POP) visando o cumprimento das } \\
\text { etapas do processo }\end{array}$ \\
\hline & & & & & & & & & Tratamento alternativo de baixo custo \\
\hline \multirow{2}{*}{$\begin{array}{l}\text { Geração de } \\
\text { efluentes } \\
\text { perigosos }\end{array}$} & $\begin{array}{l}\text { Falha no sistema de } \\
\text { coleta }\end{array}$ & \multirow{2}{*}{$\begin{array}{l}\text { Contaminação das águas e } \\
\text { do solo }\end{array}$} & \multirow{2}{*}{5} & \multirow{2}{*}{3} & \multirow{2}{*}{5} & \multirow{2}{*}{$\begin{array}{l}\text { Armazenamento em } \\
\text { bombonas na sala de } \\
\text { rejeitos para descarte por } \\
\text { empresa especializada }\end{array}$} & \multirow{2}{*}{75} & \multirow{2}{*}{ M } & $\begin{array}{c}\text { Garantir } 100 \% \text { de gerenciamento e } \\
\text { operacionalidade por meio de registro das } \\
\text { amostras em bombonas }\end{array}$ \\
\hline & $\begin{array}{l}\text { Frequência muito baixa } \\
\text { de recolhimento pela } \\
\text { empresa especializada }\end{array}$ & & & & & & & & $\begin{array}{l}\text { Aumentar a frequência da coleta pela } \\
\text { empresa especializada }\end{array}$ \\
\hline
\end{tabular}

HOLOS, Ano 35, v.8, e9189, 2019 